\title{
XLVI. The effect of combined stresses on the eleastic properties of iron and steel
}

\section{E.L. Hancock}

To cite this article: E.L. Hancock (1906) XLVI. The effect of combined stresses on the eleastic properties of iron and steel , Philosophical Magazine Series 6, 12:70, 418-425, DOI: 10.1080/14786440609463554

To link to this article: http://dx.doi.org/10.1080/14786440609463554

曲 Published online: 16 Apr 2009.

Submit your article to this journal $₫$

Џ Article views: 3

Q View related articles $\square$

4 Citing articles: 2 View citing articles ๘ 


\section{Prof. E. L. Hancock on the Effect of Comlined}

the inner layers to the surface sufficiently large to give the delays. If we now revert to the cases where the exposed plate receives an electric charge, as was the method of procedure in the majority of the experiments, it is obvious that a metal will hold a charge with a greater force the more electrons it has lost, and this being the case we shall have rates of discharge and curves of the same nature in both series of experiments. We suggest that the experiments described furnish a step in the determination of the rate at which the various forms of matter are undergoing disintegration under normal conditions.

Chemical Laboratory,

University College, London, July 1906 .

XLVI. The Effect of Combined Stresses on the Elastir Properties of Iron and Steel. By E. L. Hancock, Assistant Professor of Applied Mechanics, Purdue University, La Fayette, Indiana*.

\section{[Plate VIII.]}

THE tests reported below were carried out as a part of the "programme of work" outlined by the writer, and rresented to the American Society for Testing Materials in a "Preliminary Report of the Effect of Combined Stresses on the Elastic Yroperties of Iron and Steel" (see Proceedings of the Society, 1905). This report gave the results of tests on certain specimens of low carbon-steel and nickel-steel. The specimens were tested in tension while under different torsional stresses, i. e. in tension while under torsion to onethird, two-thirds, and the full elastic limit in torsion, respectively. The results showed that the torsional stresses lowered the elastic limit in tension.

The additional tests reporte $\mathrm{d}$ in this paper were made, for the most part, on steel tubing, the method of testing and general procedure being about the same as that reported for the pickel-and carbon-steel solid rounds. Some tests were also made on low curbon-steel solid rounds in compression while under torsion, the latter being the beginning of a series of tests in compression-torsion. Only a part of the results of these tests is included in this report. The tests were all made under the direction of the writer in the Laboratory for T'esting Materials of Purdue University. Acknowledgment is here

* Communicated by the Author, having been read before the American Society for Testing Materials, June 1906. 
Stresses on the Elastic Properties of Iron and Steel. 419

made of the help given by Messrs. Carl Wagner, H. N. Hubbard, N. L. Arbuckle, O. L. Arbuckle, R. Elsea, W. Thornton, and J. T. Voshell, senior students in engineering, in connexion with the tests.

\section{Materials.}

It is known that, when a solid bar is subjected to torsion, the outer fibres are stressed to the elastic limit first, and that the stress varies linearly to zero at the centre. It was evident that, in the case when a solid round was tested in tension while under torsion to, or beyond, its elastic limit in torsion, considerable tensional elasticity would be shown, since in such a case there would be a certain body of fibres in the interior of the piece that had not been stressed to their elastic limit. It was thought that by doing away with this interior core and using hollow tubes, the true effect of combined tension and torsion would be more nearly shown. It will be seen in what follows that the results of tests on thin tubing do not differ materially from those obtained from the tests of thick tubing and solid rounds, except as regards unit elongation at the elastic limit (see Plate VIII. fig. 6). It is the opinion of the writer at this time that nothing new would be learned by using a thinner tubing than was used in these tests.

The steel tubing used in the torsion-tension tests had an outside diameter of 1 inch. Three different thicknesses were used as follows : $0.05 \mathrm{inch}, 0.075 \mathrm{inch}$, and $0.25 \mathrm{incb}$, giving an inside diameter of $0.90 \mathrm{inch}, 0.85 \mathrm{inch}$, and 0.50 inch respectively. The tubes were thoroughly annealed before using and were, as nearly as possible, of uniform thickness. About forty torsion-tension tests were made on this material.

The material used in the torsion-compression tests was low carbon-steel solid rounds:-The test pieces were 8 inches long over all, and turned down to 3 inch with a gauge portion turned down to $\frac{1}{2}$ inch diameter. This material was from the same shipment as the low carbon-steel used in the torsiontension tests.

$$
\text { Method of Test. }
$$

The apparatus used in making the tests on steel tubing was the same as that used in testing the nickel and carbon steel solid rounds (see Preliminary Report*).

To make the torsion-compression tests, however, one ballbearing head of the apparatus was placed on the platform of the macbine and the other attached to the moving head. With the specimen inserted and under the desired torsional 
load, a compression test was made by lowering the moving head. The amount of compression was measured by means of an Olsen Compressometer. The details of these torsioncompression tests will be given in a subsequent report.

\section{Results.}

The lowering of the elastic limit in tension due to the presence of various torsional stresses is shown in Plate VIII. figs. 1,4 , and 6 (3) (for steel tubing 0.85 inch inside diameter). In this case the amount of torsional load applied was sufficient to stress the piece to $\frac{1}{3}$, $\frac{4}{3}$, and full elastic limit in torsion respectively. Fig. 2 shows the lowering of the elastic limit in tension of steel tubing 0.90 inch inside dianeter, the torsion being applied in the same way as in the case of the pieces represented in fig. 1. Figs. 4 and 6 also show this same lowering of the elastic limit. In each of the cases $A$ and $B$ the curves represent an average of two or more tests. Fig. 3 shows the effect of torsion on the elastic limit in tension of steel tubing 0.50 inch inside diameter. In this case the torsional load was applied and the piece tested in tension as indicated on the curves. Each curve represents an average of three or more tests. The lowering of the elastic limit in tension is also shown for this ease by figs. 4 and $6(3)$.

Fig. $6(3)$ shows graphically the lowering of the elastic limit in tension for various degrees of torsion, and includes, in addition to the steel tubing, the results obtained from the nickel- and carbon-steel solid rounds (see Preliminary Report). The ordinates represent the percentage of lowering of the elastic limit and the abscissæ the amount of torsional stress applied. A similar statement is true for the rest of the diagrams in fig. 6 as well as for those in figs. 4 and 5 . It is seen from this representation on fig. 6 that the variation in the elastic limit is a linear one, and might be represented by a straight line. Fig. 4 shows this straight line with the individual points represented. The equation of the line, referred to the horizontal and vertical lines as axes, might be written

$$
y=\left(p / 2 p_{s}\right)\left(2 p_{s}-x\right),
$$

where $p$ and $p_{s}$ represent unit simple tension and unit simple torsion respectively. This same lowering of the elastic limit is shown in Tables I. and II. Table I. also shows the lowering of the elastic limit of low carbon-steel in compression due to different torsional stresses. These latter results are shown graphically in comparison with those of the 
torsion-tension tests in fig. 5. This compression line, however, only holds, so far as known, for low carbon-steel.

The variation of the unit elongation at the elastic limit for different torsional stresses is shown graphically in fig. 6 (2). It is seen that, with the exception of the cases $A$ and $B$ (i. e. steel tubing 0.85 and 0.90 inch inside diameter), the torsional stress lowers the unit elongation at the elastic limit. Fig. 6 (1) also shows the change in the modulus of elasticity in tension caused by the different torsional loads. There seems to be no regularity in this case, althongh in most cases the modulus of elasticity was lowered slightly by the torsional stress.

The results of the tests, as shown by the curves, might be summed up in the statement, that the presence of a torsional stress lowers the unit stress and unit strain at the elastic limit in tension and also lowers the modulus of elasticity, somevhat. These same facts are also shown by Table I.

TABLE I.

\begin{tabular}{|c|c|c|c|c|}
\hline Stress Applied. & $\begin{array}{c}\text { Inside } \\
\text { Diameter } \\
\text { in } \\
\text { inches. }\end{array}$ & $\begin{array}{l}\text { Elastic } \\
\text { Limit in } \\
\text { pounds per } \\
\text { sq. inch. }\end{array}$ & $\begin{array}{c}\text { Modulus of } \\
\text { Elasticity in } \\
\text { pounds per } \\
\text { sq. inch. }\end{array}$ & $\begin{array}{l}\text { Unit } \\
\text { Elongation } \\
\text { at Elastic } \\
\text { Limit in } \\
\text { inches. }\end{array}$ \\
\hline $\begin{array}{l}\text { Stcel Tubing. } \\
\text { Simple Tension....... } \\
\text { 1/3 Tors.-El. Ten... } \\
\text { 2/3 Tors.-El. Ten... } \\
\text { 3/3 Tor.-El. Ten... } \\
\text { Simple Tension..... } \\
\text { 1/3 Tors.-El. Ten... } \\
\text { 2/3 Tors.-El. Ten.... } \\
\text { 3/3 Tors.-El. Ten.... } \\
\text { Simple Tension..... } \\
\text { 1/6 Tors.-El. Ten... } \\
\text { 2/6 Tors.-El. Ten.... } \\
\text { 3/6 Tors.El. Ten.... } \\
4 / 6 \text { Tors.-El. Ten.... } \\
\text { 5/6 Tors.-El. Ten.... } \\
\text { 6/6 Tors.-El. Ten.... }\end{array}$ & $\begin{array}{l}0.85 \\
0.85 \\
0.85 \\
0.85 \\
0.90 \\
0.90 \\
0.90 \\
0.90 \\
0.50 \\
0.50 \\
0.50 \\
0.50 \\
0.50 \\
0.50 \\
0.50\end{array}$ & $\begin{array}{r}17,000 \\
16,000 \\
12,090 \\
8,000 \\
28,000 \\
24,000 \\
17,000 \\
14,000 \\
20,000 \\
18,000 \\
16,000 \\
14,000 \\
12,000 \\
10,000 \\
8,000\end{array}$ & $\begin{array}{l}27,400,000 \\
26,600,000 \\
27,200,000 \\
17,000,000 \\
29,700,000 \\
27,800,000 \\
25,000,000 \\
16,200,000 \\
33,300,000 \\
27,200,000 \\
29,600,000 \\
28,000,000 \\
26,000,000 \\
30,300,000 \\
26,600,000\end{array}$ & $\begin{array}{l}.00062 \\
.00060 \\
.00044 \\
.00053 \\
.00094 \\
.00086 \\
.00068 \\
.00086 \\
.00080 \\
.00066 \\
.00054 \\
.00050 \\
.00046 \\
.00033 \\
.00030\end{array}$ \\
\hline $\begin{array}{r}\text { Nickel-Steel Solid Roun } \\
\text { Simple Tension ...... } \\
\text { 1/3 Tors.-El. Ten.... } \\
\text { 2/3 Tors.-El. Ten.... } \\
\text { 3/3 Tors.-El. Ten.... }\end{array}$ & $\begin{array}{l}\ldots \ldots . . \\
\ldots \ldots . \\
\ldots \ldots . . \\
\ldots \ldots .\end{array}$ & $\begin{array}{r}56,000 \\
52,000 \\
44,000 \\
20,000\end{array}$ & $\begin{array}{l}35,000,000 \\
29,800,000 \\
28,800,000 \\
28,800,000\end{array}$ & $\begin{array}{l}.0016 \\
.00174 \\
.00152 \\
.0067\end{array}$ \\
\hline $\begin{array}{l}\text { Low Carbon-Steel Solid } \\
\text { Simple Tension...... } \\
\text { 1/3 Tors-El. Ten... } \\
\text { 2/3 Tors.El. Ten... } \\
\text { 3/3 Tors.-El. Ten.... }\end{array}$ & $\begin{array}{l}\text { ounds. } \\
\ldots \ldots . . \\
\cdots \cdots . . \\
\cdots \cdots . . \\
\cdots \cdots\end{array}$ & $\begin{array}{l}34,000 \\
32,000 \\
24,000 \\
16,000\end{array}$ & $\begin{array}{l}30,800,000 \\
30,500,000 \\
25,800,000 \\
25,200,000\end{array}$ & $\begin{array}{l}.0011 \\
.00105 \\
.00083 \\
.00063\end{array}$ \\
\hline
\end{tabular}




\section{Prof. E. L. Hancock on the Effect of Combined}

It is interesting at this time to see the results obtained by substituting the results obtained from these tests in the various formulæ used for determining the unit stresses for the case of combined stresses. The formulæ generally used in designing parts subjected to combined flexure and torsion, tension and torsion, and compression and torsion, are as follows:-

$$
\begin{aligned}
& q_{1}=(1 / 2)\left[p+\sqrt{\left.p^{2}+4 p_{s}^{2}\right)}, \ldots . .\right. \\
& q_{s}=(1 / 2) \sqrt{p^{2}+4 p_{s}^{2}}, \quad . \quad . \quad . \quad .
\end{aligned}
$$

where $q_{1}$ represents the greatest unit tension on any internal plane, $q_{s}$ the greatest unit shear on any internal plane, $p$ the unit simple tension, and $p_{s}$ the unit simple shear. The formulæ give the apparent unit tension and shear acting on any particle of the body. To obtain the true maximum unit stresses on any internal plane it is necessary to take account of the lateral contraction as well as the elongation, $i . e$. it is necessary to use Poisson's ratio. Taking this ratio as $1 / 4$ (Johnson, 'Materials of Construction'), the formulæ giving the maximum unit tension and the maximum unit shear on any internal plane are

$$
\begin{aligned}
& \mathrm{T}_{1}=(3 / 8) p+(\bar{\jmath} / 8) \sqrt{\left(p^{2}+4 p_{s}^{2}\right)}, \quad . \quad . \quad . \\
& \mathrm{T}_{s}=(5 / 8)\left(\sqrt{p^{2}+4 p_{s}^{2}}\right) . \quad . \quad . \quad . \quad . .
\end{aligned}
$$

Or using Poisson's ratio as $1 / 3$ (Merriman, 'Mechanies of Materials,' 1905), the maximum unit stresses are

$$
\begin{aligned}
& \mathrm{T}_{1}{ }^{\prime}=(1 / 3) p+(2 / 3) \sqrt{p^{2}+4 p_{s}{ }^{2}}, \quad . \quad . \quad . \\
& \mathrm{T}_{s}{ }^{\prime}=(2 / 3) \sqrt{p^{2}+4 p_{s}{ }^{2}} . \quad . \quad . \quad . \quad . \quad .
\end{aligned}
$$

Formulæ (1), (2), (3), (4), (5), and (6) have been used in constructing Table II. For this purpose $p$ was taken as the unit stress at the elastic limit in tension and $p_{s}$ the unit torsional stress on the specimen. The unit stresses thus obtained, whether apparent or real, which are greater than the simple unit stress, are underlined. For example, low carbonsteel shows a unit stress in simple tension at the elastic limit of 34,000 and a unit shear at the elastic limit in torsion of 30,000 , when beld in torsion at one-third the elastic limit (corresponding to a fibre stress of 12,540 ), and tested in tension 
Siresses on the Elastic Properties of Iron and Steel.

the elastic limit was found to be 32,000 ; taking $p$ as 32,000 and $p_{s}$ as 12,540 , the apparent and true stresses given in the same line have been calculated. This same procedure was followed in constructing the entire table. It is scen that the apparent maximum unit shear is generally less than the shearing strength of the material, and that the true maximum unit shear is generally greater than the shearing strength of the material (here shearing strength means the elastic strength as determined from torsion tests), higher values being given for the case where Poisson's ratio was taken as $1 / 3$. In only a few cases in the case of the solid rounds and the thick tubing did the apparent maximum tension exceed the tensile strength of the material (tensile strength meaning unit tensile stress at the elastic limit in simple tension); the number of cases where the true maximum tensile stresses, for solid rounds and thick tubes, exceed the tensile strength of the material is greater than the corresponding number for the apparent stresses. In the case of the thin tubing, however, it is seen that in no case did the apparent maximum unit stress or the true maximum unit stress in tension reach the elastic strength of the material; but in the case of maximum unit shear the true stresses are grcater than the elastic strength of the material (not true for apparent maximum shear, except in one case). In general, it is seen from this table that the formula for true unit stresses with Poisson's ratio as $1 / 3$ give the highest values, those with Poisson's ratio as $1 / 4$ the next highest, and the formulæ for apparent stresses the lowest. This is shown graphically for the carbon and nickel steel solid rounds by tig. 7 .

The conclusion to be drawn from Table II. is that in the design of parts subjected to combined stresses the true shearing strength should be used. Mr. J. J. Guest, whose investigation was referred to in the Preliminary Report, arrived at the same conclusion as the result of his investigations. The entire uniformity of the results as shown by the thin tubing, where the effect of the combined stresses can be more exactly determined, gives the confidence in this conclusion, in spite of the fact that the maximum tension is usually supposed to govern the design of parts subjected to combined stresses. 


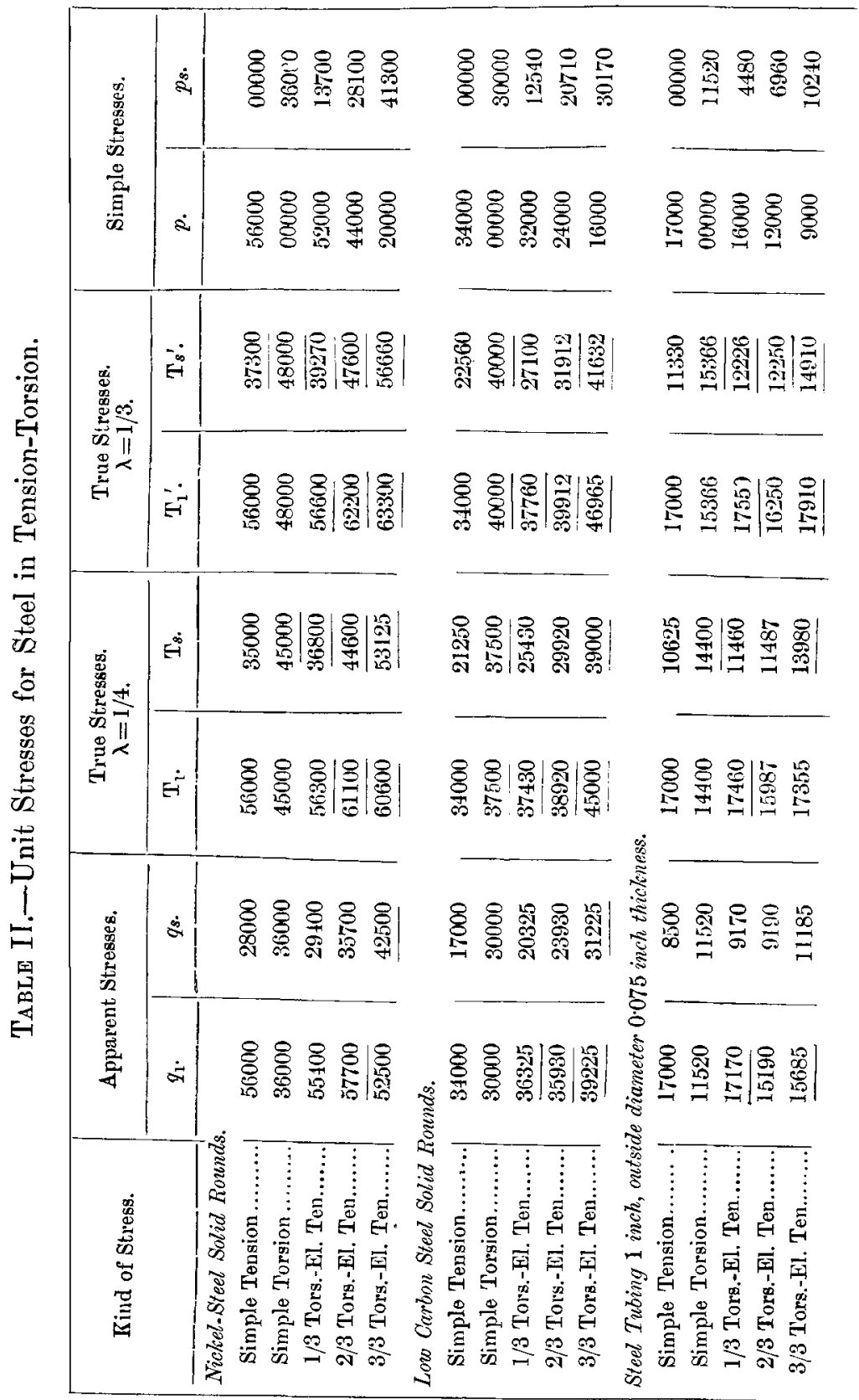


Stresses on the Elastic Properties of Iron and Steel. 425

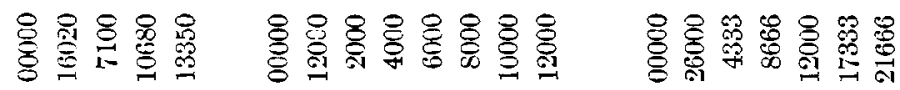

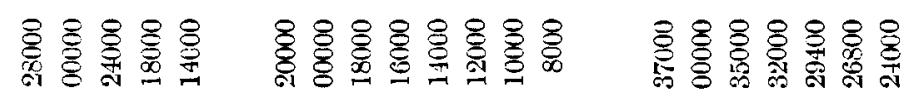

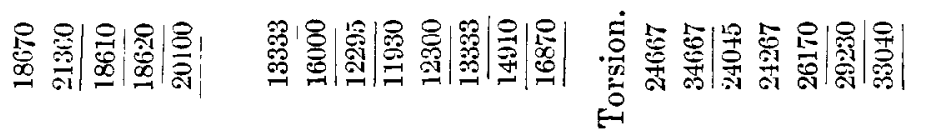

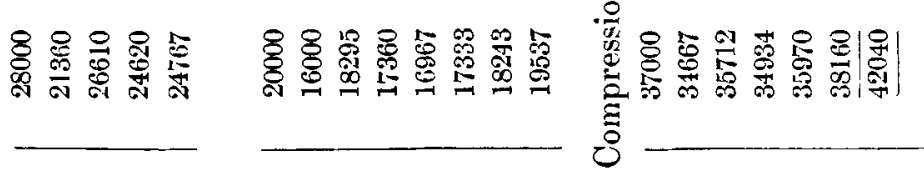

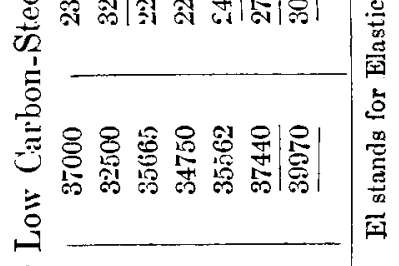
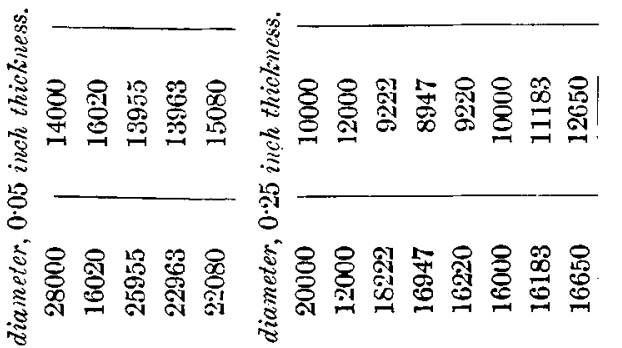

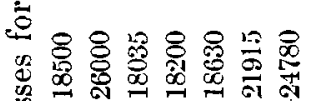

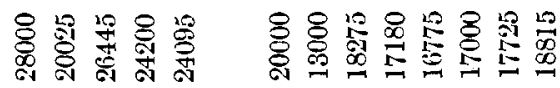

事

ฐัฐ

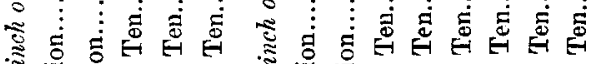

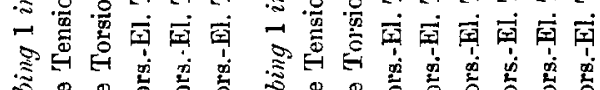

今。

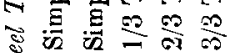

औै

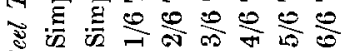

読

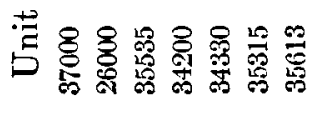

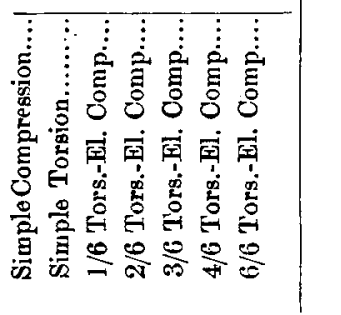




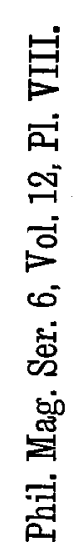
